\title{
Ficção científica e ensino de ciências: para além do método de 'encontrar erros em filmes'
}

\author{
Luís Paulo Piassi \\ Maurício Pietrocola \\ Universidade de São Paulo
}

\section{Resumo}

Obras de ficção científica têm sido apontadas como um recurso importante para o ensino de ciências. Entretanto, mais do que um possível recurso didático para facilitar o aprendizado de ciências, a ficção científica constitui por si só uma modalidade de discurso sobre a ciência na medida em que expressa, por meio do cinema e da literatura, interesses e preocupações em torno de questões científicas presentes que influem diretamente no âmbito sociocultural. É comum, entretanto, considerar a possível qualidade didática das obras ficcionais apenas em função da suposta correção científica dos conceitos que apresenta, procedimento esse que ignora as condições de produção do discurso ficcional. Neste trabalho, propõe-se uma metodologia de análise do conteúdo de obras de ficção científica em sua relação com o conhecimento científico, que procura evidenciar, mediante elementos de análise literária e de semiótica, o processo de construção daquilo que denominamos elementos contrafactuais. Tal análise assume a obra não como um simples recurso didático, mas como um discurso regido por mecanismos ficcionais e que se vale desses mecanismos para veicular posições, ideias e debates em torno de temas científicos atuais. Como resultado, foi produzida uma categorização dos elementos construída a partir da semiótica greimasiana, empregando uma base de traços distintivos assumidos como lexemas, para a elaboração das categorias. Cada uma dessas categorias, ao representar mecanismos narrativos distintos, tem a potencialidade de uma forma de exploração diferente em termos didáticos.

\section{Palavras-chave}

Ficção científica - Literatura - Cinema - Ensino de ciências.

Correspondência:

Luís Paulo Piassi

Escola de Artes, Ciências e Huma-

nidades da USP

Rua Arlindo Béttio, 1000

03828-000 - São Paulo - SP

e-mail: Ippiassi@usp.br 


\title{
Science fiction and the teaching of science: beyond the method of 'finding errors in movies'
}

\author{
Luís Paulo Piassi \\ Maurício Pietrocola \\ Universidade de São Paulo
}

\begin{abstract}
Works of science fiction have been pointed as an important resource in the teaching of science. However, more than a possible didactic resource to facilitate the learning of science, science fiction constitutes in itself a modality of discourse about science, insofar as it expresses through cinema and literature, interests and concerns about current scientific issues that impact directly on the socio-cultural sphere. It is, nevertheless, common to regard the possible didactic quality of fictional works only in terms of the supposed scientific correction of the concepts they present, an attitude that ignores the conditions of production of the fictional discourse. In the present work a methodology is proposed to analyze the content of works of science fiction in their relation to scientific knowledge, trying to reveal through elements of literary analysis and semiotics the process of construction of what we called counterfactual elements. The present analysis views the work of fiction not just as a simple didactic element, but as a discourse governed by fictional mechanisms, and that makes use of these mechanisms to convey positions, ideas and debates around current scientific themes. As a result, a categorization of these elements was developed based on the Greimasian semiotics, employing a set of distinctive features assumed as lexemes in the definition of the categories. By representing distinct narrative mechanisms, each one of these categories has the potential to be explored differently in didactic terms.
\end{abstract}

\section{Keywords}

Science fiction - Literature - Cinema - Teaching of science.

Contact:

Luís Paulo Piassi

Escola de Artes, Ciências e Huma-

nidades da USP

Rua Arlindo Béttio, 1000

03828-000 - São Paulo - SP

e-mail: Ippiassi@usp.br 
Tem sido comum a proposta de empregar filmes de ficção científica - FC - para introduzir conceitos de ciência em sala de aula (Southworth, 1987; Martin-Diaz et al., 1992; Dubeck et al., 1990; 1993; 1998; Freudenrich, 2000; Dark, 2005). No entanto, muitas vezes, o potencial didático de uma obra é associado à precisão científica das situações retratadas. Assim, filmes que exibem cenas fantasiosas ou mesmo flagrantemente contrárias ao conhecimento científico seriam didaticamente menos relevantes do que as que trazem situações realistas.

Nas pesquisas em ensino de ciências, no entanto, a noção de "erro" conceitual tem sido examinada com critérios menos valorativos, seja por aquelas baseadas no desenvolvimento cognitivo, derivadas dos trabalhos pioneiros de Viennot (1979) e de Saltiel e Viennot (1985), seja pelas ligadas à história e à natureza do conhecimento científico, que mostram como o desenvolvimento do conhecimento no plano individual está sujeito a indefinições e obstáculos similares aos da construção do conhecimento social da ciência, aspecto já destacado nos anos 1980 por Gilbert e Zylbersztajn (1985). Além disso, também não é possivel ignorar que a obra ficcional segue suas próprias leis: aquilo que um cientista consideraria um erro pode constituir uma estratégia narrativa fundamental para que a história atinja o efeito pretendido pelo autor.

Nessas duas vertentes do erro - etapa do conhecimento e estratégia narrativa - há um aspecto em comum: a apreensão do real a partir de conceitos para representar o mundo por meio da linguagem. As pesquisas em ensino mencionadas baseiam-se, sobretudo, em dados da expressão verbal dos estudantes sobre fenômenos e situações. São narrativas sobre o mundo, calcadas em experiências que embora possuam referências na vivência direta com o mundo, são predominantemente representações culturais coletivas da ciência. A FC, por outro lado, destrincha essas experiências culturais a partir de ideias científicas e colocam-nas sob a perspectiva das questões humanas a elas subjacentes.
Interessa verificar se tais aspectos do erro (etapa de aprendizagem e procedimento narrativo) são epistemologicamente conciliáveis, de forma a ser possível estabelecer entre eles uma relação de necessidade. Se não, a ficção será quando muito um simples recurso para estimular o estudante e facilitar o ensino. Entretanto, se há uma relação intrínseca entre a questão conceitual da ciência e a lógica ficcional, talvez seja possível encontrar nas obras de ficção algo mais profundo do que uma simples estratégia agradável de ensino.

\section{A ficção científica}

A FC moderna tem origem no final do século XIX com Júlio Verne e H. G. Wells, autores que influenciaram decisivamente as obras subsequentes do gênero. Enquanto Verne produzia histórias para maravilhar os leitores com as possibilidades de um futuro excitante, Wells empregava a fantasia científica para a crítica social. Na década de 1920, nos EUA, os contos voltados para um público popular deu impulso à FC, conferindo-lhe características singulares como forma de criação literária que depois veio a influenciar decisivamente outros gêneros de entretenimento popular como o cinema, os seriados de TV, os quadrinhos e os desenhos animados.

Contudo, o que é a FC afinal? A maior parte dos autores reconhece a dificuldade de estabelecer uma definição precisa. Asimov (1984), por exemplo, a insere em um gênero mais geral - a ficção surrealista - que retrataria "fatos que se verificam em ambientes sociais não existentes na atualidade e que jamais existiram em épocas anteriores". Na FC, em particular, tais fatos "podem ser concebivelmente derivados do nosso próprio meio social, mediante adequadas mudanças ao nível da ciência e da tecnologia" (p. 16).

Para Allen (1976), a FC distingue-se "de outros tipos de ficção pela presença de uma extrapolação dos efeitos humanos de uma ciência extrapolada" (p. 235). Entendemos a ciência extrapolada de Allen como uma categoria que 
engloba qualquer forma de utilização de ideias científicas para a produção do conteúdo veiculado no texto, ou seja, ela não é o conteúdo em si, mas uma diretriz para sua construção.

Umberto Eco (1989) se aproxima de Asimov ao propor que, na FC, "a especulação contrafactual de um mundo estruturalmente possivel é conduzida extrapolando, de algumas linhas de tendência do mundo real, a possibilidade mesma do mundo futurivel", e também de Allen ao enfatizar o aspecto de antecipação da FC que, segundo ele, "assume a forma de uma conjetura formulada a partir de linhas de tendência reais do mundo real" (p. 169, grifos do autor). A antecipação, fundada na racionalidade científica, serve assim a uma especulação a respeito do mundo real. Para o autor,

[...] a boa ficção científica é cientificamente interessante não porque fala de prodígios tecnológicos [...], mas porque se apresenta como um jogo narrativo sobre a própria essência de toda a ciência, isto é, sobre a sua conjeturabilidade. (p. 170)

Na mesma linha, Rabkin (1977) afirma que "a variação a partir do conhecimento aceito é uma das características definidoras do gênero de ficção científica", acentuando que "o que é importante na definição da ficção científica não são as justaposições de armas de raios e aventais de laboratório, mas os hábitos mentais "científicos"” (p. 120-121).

Suvin (1984), por sua vez, afirma que "pode-se diferenciar a ficção científica pelo domínio ou hegemonia narrativa de um 'novum' (novidade, inovação) validado mediante a lógica cognoscitiva" (p. 94), sendo esse novum entendido principalmente como a lógica de fundo científico, da disposição mental que a narrativa induz.

Entende-se assim a FC não como um gênero que possui qualquer relação com a ciência, mas sim que emprega uma racionalidade do tipo científica para produzir conjeturas sobre a realidade. Por meio da derivação ou variação, sua narrativa é pautada pela conjetura dentro dos limites da racionalidade lógico-causal. É orientada para a exploração dos efeitos humanos decorrentes do estabelecimento de um novum, que é disparador de conjeturas. Daí decorre seu efeito literário.

Um último aspecto fundamental, que terá repercussões especialmente relevantes no uso da FC no ensino de ciências, é o chamado sense of wonder:

[...] que pressupõe a presença de um fato extraordinário interpenetrando a consciência do real e do cotidiano, causando, em alguma medida, o choque entre o que a consciência admite como parte de sua experiência imediata, e esse algo novo que vem desafiar a experiência. (Causo, 2003, p. 78)

Tal choque ou perplexidade se torna mais importante e eficaz quando o contrafactual que o produz estabelece uma ligação com o real em termos de possibilidades sustentadas pela razão, que é o que faz o discurso da FC. Nesse sentido, Suvin (1984) chama a atenção para o aspecto de cognição, e Peter Nicholls (apud Causo, 2003) estabelece o conceito de "avanço conceitual".

Não se trata de mero espanto e estranhamento frente ao incomum, que ocorre em histórias de terror ou fantasia, mas de um estranhamento que obriga a pensar no incomum como uma conjetura plausível e lógica, aplicável ao mundo fora da ficção. Tal estranhamento terá apoio em elementos presentes na obra, construídos pelo processo de derivação a partir do ambiente empírico do autor (Suvin, 1984), ao mesmo tempo em negação e em continuidade com ele.

A expressão "especulação contrafactual" de Eco nos dá uma chave para caracterizar tais elementos. Contrafactual remete à contraposição de fatos. Pode-se, por exemplo, imaginar um animal falante, que nega o fato de que animais não falam. Uma narrativa pode optar por um caminho não conjeturativo da negação como faz George Orwell (1971) em A revolução dos bichos, que não está preocupado em examinar consequências do tipo "e 
Tabela 1: Exemplo de semas como traços distintivos formando diversos lexemas.

\begin{tabular}{|l|c|c|c|c|c|c|c|c|c|}
\hline & $\begin{array}{c}\text { Para cobrir } \\
\text { a cabeça }\end{array}$ & $\begin{array}{c}\text { Com } \\
\text { copa }\end{array}$ & Com copa alta & $\begin{array}{c}\text { Com } \\
\text { abas }\end{array}$ & $\begin{array}{c}\text { Com abas } \\
\text { largas }\end{array}$ & $\begin{array}{c}\text { Com pala sobre } \\
\text { os olhos }\end{array}$ & $\begin{array}{c}\text { De material } \\
\text { flexivel }\end{array}$ & $\begin{array}{c}\text { Ajustável } \\
\text { à cabeça }\end{array}$ & Masculino \\
\hline Boné & + & + & - & - & - & + & + & + & $+/-$ \\
\hline Gorro & + & + & - & - & - & - & + & + & $+/-$ \\
\hline Sombreiro & + & + & - & + & + & - & + & - & + \\
\hline Panamá & + & + & - & + & - & - & + & - & + \\
\hline Cartola & + & + & + & + & - & - & + & - & + \\
\hline Coco & + & + & - & + & - & - & - & - & + \\
\hline Boina & + & + & - & - & - & - & + & - & $+/-$ \\
\hline Quepe & + & + & - & - & - & + & - & - & + \\
\hline Chapelina & + & + & - & + & $+/-$ & - & + & - & - \\
\hline
\end{tabular}

se os bichos falassem, como seria a nossa vida?". Não há novum, já que os limites da racionalidade lógico-causal não são considerados e a continuidade espaço-temporal, ignorada. Caso diferente é o filme $O$ planeta dos macacos (Schaffner, 2000), no qual a fala dos animais está inscrita em uma continuidade espaço-temporal (ocorre no nosso futuro), da racionalidade lógico-causal (o processo que leva os macacos a falar é cognoscível dentro da racionalidade científica) e a conjeturabilidade ocorre em termos de efeitos humanos: a guerra nuclear destrói nossa civilização, e os macacos nos subjugam. Na FC, a construção do contrafactual acontece, portanto, a partir de um fato conhecido cientificamente, contrapondo-se a ele por meio da apropriação do discurso científico, seja mediante o plano da expressão (terminologias, léxicos, imagens), seja por intermédio do plano do conteúdo (conceitos, relações, processos de raciocínio).

\section{Elementos contrafactuais: os traços distintivos}

Para investigar o contrafactual na FC a partir de sua relação com o arcabouço de conceitos, leis e fenômenos da ciência e do conhecimento tácito comum, procuraremos construir uma categorização que elucide sua construção a partir de aspectos internos ao texto e de referências ao conhecimento suposto do conteúdo científico nele veiculado. Para a construção das categorias, adaptaremos a análise de traços distintivos da semântica greimasiana (Greimas, 1976), que considera possível mapear o aspecto semântico de uma palavra ou, mais precisamente, um item lexical ou lexema a partir de componentes fundamentais, que seriam unidades mínimas de significado. Como analogia, tais unidades mínimas - denominadas semas - seriam elementos ou átomos que, combinados de diferentes formas, constituiriam diferentes substâncias ou moléculas. 0 estabelecimento do conjunto fundamental de semas tem, no entanto, certo grau de arbitrariedade, que depende do conhecimento do significado do item lexical. Um exemplo com peças de vestuário da categoria dos chapéus é dado por Pietroforte e Lopes (2005, p. 119):

Cada lexema (boné, gorro etc.) é dado pela presença, ausência ou indiferença de certos traços distintivos (com copa, com abas etc.), que são os semas, ou seja, cada categoria é "caracterizada pela presença de certo número de semas e pela ausência de outros" (Greimas, 1976, p. 48). Os semas formam uma base de traços distintivos independentes a partir da qual cada categoria é delimitada, de forma a distinguir termos que possuem significados próximos, como é o caso dos diversos tipos de chapéus.

Com isso, é possivel construir categorias com base em critérios razoavelmente bem delimitados, com a vantagem de ser uma categorização expansível e não exaustiva. A partir de um conjunto ${ }^{1}$ de filmes e contos de FC, é possível verificar as diversas categorias de elementos contrafactuais e que cada uma dessas categorias

1. No final do artigo, para facilitar a consulta, há uma lista em separado das obras empregadas para verificação das categorias apresentadas. 
desempenha um papel diferente na narrativa e produz diferentes efeitos no todo. Sentimos que seria importante delimitar essas diferentes categorias de uma forma razoavelmente precisa, e assim utilizarmos a semântica greimasiana, construindo um conjunto de semas que formam a base para a construção das categorias em si, consideradas como lexemas.

Embora o uso de marcadores binários não seja capaz de captar determinadas nuances intermediárias, a partir dos traços distintivos, podemos construir categorias de elementos contrafactuais razoavelmente delimitadas no que se refere à relação da construção literária com o conhecimento científico e com as suas correspondentes possibilidades de análise em contexto didático. Passemos então a definir um conjunto de traços distintivos independentes que empregaremos como base na construção de nossas categorias de elementos contrafactuais:

[científico]: Elemento contrafactual que é (ou não) construído por associação ao discurso científico. Uma arma laser, por exemplo, é geralmente [+científico] e um gnomo, em geral, [-científico]. A classificação, no entanto, depende da análise específica da obra, o que valerá também para os demais traços distintivos. Embora consideremos possivel - e até importante - a análise das possibilidades didáticas de elementos contra-factuais do tipo [-científico], acreditamos que tal estudo requer considerações teóricas que vão além do escopo deste trabalho, de forma que todas as categorias aqui analisadas possuirão a marca [+científico].

[sobrenatural]: Elemento contrafactual que tenha (ou não) implícito em sua construção origens não cognoscíveis de acordo com pensamento lógico causal típico da ciência, tais como a magia, a mitologia e a religião. Independentemente da origem, tal aspecto introduz complicadores na análise a partir do repertório científico, o que exigiria (e mereceria) um estudo à parte. No presente estudo, vamos nos ater a elementos que possam ser indicados como [-sobrenatural].

[real]: Atribuição (ou não), ao elemento contrafactual, de um caráter de realidade presente, de existência real e constatável no mundo empírico do autor e de seu "leitor implícito", entendido aqui como define Todorov (2004). É bom observar que a realidade em si do elemento, no mundo real fora do texto da obra, é irrelevante: o discurso da obra é que assume a realidade desse fato em pacto implícito com o leitor.

[extraordinário]: Elemento contrafactual construído e considerado (ou não) como extraordinário em relação à percepção do leitor implícito. Animais falantes são extraordinários, mas barulhos no vácuo do espaço não o são quando o discurso da obra os assume como algo comum, esperado pelo espectador.

[inusitado]: Elemento contrafactual construído e considerado (ou não) como extraordinário na percepção dos personagens. Observemos que algo não extraordinário (um sapato, por exemplo) para o leitor implícito pode ser desconhecido pelos personagens.

[possivel]: Elemento contrafactual assumido (ou não), pelo discurso da obra, como possível, de acordo com o conhecimento científico presente. Deve considerar o contexto da criação literária, ou seja, a verificação de se o discurso pressupõe que o elemento seja possivel de acordo com a ciência.

[explicado]: Elementos contrafactuais para os quais a narrativa constrói (ou não) um contexto explicativo por meio de uma rede de relações ou formando um encadeamento lógico a partir de premissas assumidas como científicas.

[conceitual]: Elementos contrafactuais construídos (ou não) a partir de conceitos científicos, remetendo a concepções bem 
delimitadas e assumidas como de conhecimento do leitor implícito.

[conexo]: Elementos contrafactuais apresentados (ou não) em uma continuidade lógica construída com o mundo ficcional. Há filmes, por exemplo, em que frascos com substâncias coloridas fumegantes servem como mera ambientação, sem continuidade causal com outros constituintes da trama. Essa ausência de conexão será indicada como [-conexo]. Também marcamos como [-conexo] elementos apresentados como inexplicáveis em ruptura com relações causais imagináveis no contexto da obra.

Os cinco filmes empregados foram escolhidos dentre diversos sucessos cinematográficos amplamente conhecidos, para os quais existem diversas referências de uso didático. Determinados aspectos, mais perceptíveis a partir do texto escrito, foram extraídos de contos de FC. Acreditamos que, no geral, a análise se aplica tanto às obras escritas como aos filmes e seriados, embora existam algumas diferenças que não abordaremos neste trabalho. As categorias que construímos a partir dos diferentes traços distintivos são as seguintes:

\section{Emulativos: \\ [+científico][+real][+possível][+conexo] [-sobrenatural][-inusitado]}

Consideramos emulativos elementos que reproduzem de forma mais ou menos fiel o que é considerado como existente no mundo real. Nesse caso, o que vai distinguir a FC da obras "comuns", ditas naturalistas, é o procedimento de forçar os limites do real ao extremo, mas sem violá-los, utilizando elementos implicitamente reais [+real] e ao mesmo tempo enfatizando o caráter [+extraordinário] como, por exemplo, o asteróide em rota de colisão com a Terra de Impacto profundo (Leder, 1998). Apesar de retratarem situações supostamente previstas pelo conhecimento vigente, tais elementos retratam-nas por meio de um discurso que am- plifica seu aspecto amedrontador e suas probabilidades de ocorrência no mundo real. Geralmente, tais elementos são o centro de uma narrativa na qual outros elementos derivados do discurso tecnocientífico aparecerão, mas sem o caráter extraordinário.

Do ponto de vista didático, isso nos dá algumas possibilidades. Elementos emulativos [+extraordinário] são em geral o assunto central da história. Para que o efeito dramático ocorra, é quase certo que as falas das personagens e as relações estabelecidas no enredo constituirão um discurso [+explicado] em torno desse elemento. A análise desse discurso relativamente abundante em aspectos conceituais e fenomenológicos podem servir de base para a construção de atividades didáticas. Outro aspecto é que, muitas vezes, esse tipo de história apresenta a situação como um problema a ser resolvido. A formulação de hipóteses, os possíveis caminhos de solução, a forma de obtenção de informações, as consequências e os riscos de cada proposta de solução são aspectos que podem ser objeto de discussão em sala de aula. Elementos [-extraordinário] geralmente ajudarão a compor uma rede de relações para sustentar a verossimilhança da história. Sendo assim, embora não desempenhem um papel central no enredo, podem ser objeto de análise dentro de um encadeamento maior de elementos e suas relações.

Um dos problemas a ser considerado no trato com elementos emulativos é que o discurso do real neles implícito pode levar o leitor-espectador a uma indistinção entre o que é conhecimento científico aceito e o que é criação ficcional ou mesmo, como aponta Kirby (2003, p. 258), aceitar como consenso uma visão que na verdade pode ser o ponto de vista particular de um consultor científico que tenha trabalhado na produção da obra.

\section{Extrapolativos: [+científico][+extraordinário][+possível] [+conexo][-sobrenatural][-real]}

Para Allen (1976) são extrapolativas as histórias "que tomam o conhecimento corrente de 
uma das ciências e projetam logicamente quais podem ser os próximos passos nessa ciência” ( $p$. 22). Partindo disso, consideramos extrapolativos elementos [+possível], ou seja, que embora não possuam existência concreta, são assumidos como viáveis, a partir de projeções consensuais do conhecimento científico presente, como possibilidade técnica ou fenomenológica. 0 hotel orbital de 2001: uma odisseia no espaço (Kubrick, 1968), por exemplo, está razoavelmente inserido nas possibilidades técnicas e científicas da época, embora seu custo e viabilidade fossem impeditivos. Embora do ponto de vista lógico, o traço [+extraordinário] não seja necessário ao elemento extrapolativo. Para a história de FC, não faz sentido a introdução de um novum sem chamar a atenção para seu caráter fora do comum.

Do ponto de vista didático, os elementos extrapolativos [+explicado] fornecem material rico de discussão a respeito de conceitos, leis e fenômenos, porque permitem a análise das várias relações estabelecidas pela narrativa. Os elementos [-explicado], por sua vez, mesmo tendo papel secundário na trama, muitas vezes chamam a atenção do espectador, até porque 0 efeito de [+extraordinário] em geral é salientado pela colocação afetadamente casual do elemento na sequência dos acontecimentos. Como estamos falando de elementos [+possível], cabem atividades que proponham preencher o vazio deixado pela ausência de explicação como, por exemplo, uma questão do tipo: seria possível existir tal coisa? Além disso, algum tempo após a produção da obra, é possível que, pela evolução técnica, alguns elementos extrapolativos possuam similares no mundo real. Um debate possivel, nesse caso, é o contraste entre como o autor havia imaginado o artefato e seu uso e como ele realmente aconteceu no mundo real.

\section{Especulativos: \\ [+científico][+extraordinário][+explicado] [+conexo][-sobrenatural][-real] [-possível]}

Allen (1976) chama de especulativas histórias que imaginam um futuro mais remoto que as extrapolativas, mas que, apesar da inerente dificuldade desse processo, retratam ciências "semelhantes às ciências que conhecemos agora e [...] nelas baseadas” (p. 22). Nessa linha, definimos como especulativos elementos que se inspiram nas incertezas, especulações ou mesmo impossibilidades teóricas do conhecimento científico corrente, mantendo, porém, uma constituição conceitual fortemente ancorada na lógica científica. Tais elementos são necessariamente [-possível]. Observe-se, no entanto, que dizer o que é ou não de fato possível é muito complicado. Não é disso que se trata aqui. 0 aspecto fundamental é a impossibilidade assumida pelo discurso narrativo. Os robôs da FC são importantes justamente porque são assumidos como não possíveis: seu caráter de [+extraordinário] é construído com base em uma tensão entre essa impossibilidade assumida e uma possibilidade hipotética ou concebível.

Ideias como teletransporte, invisibilidade, robôs, alienígenas, imortalidade, viagens no tempo povoam a imaginação de todos nós e são temas reiterados em inúmeras obras, e se fazem esse sucesso, é porque devem encontrar ressonância em anseios profundos como viajar instantaneamente, passear sem ser visto, mas também em receios como a superação dos humanos pelas máquinas, a perda da privacidade e assim por diante. Isso tem consequências didáticas. 0 professor, sendo o representante do conhecimento científico na sala de aula, pode se sentir em situação crítica se tiver que responder categoricamente se são possíveis a invisibilidade ou a viagem no tempo. E se consultar livros de divulgação científica, artigos científicos ou entrevistas de cientistas, verá que essa dúvida permanece e até se acentua. Abordar em aula elementos especulativos, insere-o no campo da controvérsia, ao mesmo tempo excitante e ameaçador. Excitante porque é fundamental, é contemporâneo, é de interesse para os alunos abordar o novo, o debate atual como defendem Snyders (1988) e Durant (2005). Ameaçador porque o sistema escolar tem certa rejeição a temas controversos como observam esses mesmos autores. 
A inserção de discussões controversas em meio aos necessários conhecimentos consensuais pode acontecer por meio de um processo de continuidade: a invisibilidade e a viagem no tempo, analisadas a partir das leis ópticas e mecânicas clássicas. No entanto, a discussão completa necessariamente levará à conjetura a respeito das leis ópticas e mecânicas “imagináveis” e podem apontar para as pesquisas de hoje, os conceitos controversos atuais, as fronteiras do conhecimento. A obra de ficção coloca a invisibilidade e tudo o mais em um contexto de possibilidade imaginada e, em geral, dá uma solução, uma proposta, que pode ser analisada criticamente em função de sua coerência interna e de sua relação com os debates atuais da ciência. Tudo isso pode dar margem para atividades muito ricas e relevantes ao entrelaçar as leis e os conceitos conhecidos com os limites do conhecimento atual, as formas de produção do conhecimento e as implicações sociais daí derivadas que, em geral, são o aspecto central das obras.

\section{Anômalos:}

\section{[+científico][+extraordinário][+inusitado] [-sobrenatural][-real][-conexo]}

Denominamos anômalos elementos que são construídos por ruptura explícita com o conhecido. Esse processo é geralmente empregado para explorar alternativas de realidade, seguindo uma lógica do "e se fosse possível?". Apresenta os elementos como impossíveis, de forma muito clara: sabemos que não é possível retornar no tempo, mas e se fosse? A conexão causal com o mundo empírico, que é um dos pilares das definições de FC, está comprometida nesse caso. No entanto, às vezes, a FC se vale de elementos anômalos, e o processo pelo qual ela faz isso é muito relevante por parecer, à primeira vista, contraditório: a junção, em um mesmo elemento, do traço [-conexo] com pelo menos um dos dois traços que, a princípio, deveriam a ele se opor: o traço [+explicado] e o traço [+conceitual] como forma de produzir um efeito de estranhamento intensificado. Dois exemplos são $A$ casa quadridimensional de Robert Heinlein (1979), no qual um arquiteto construiu uma casa com o formato de um tesseract projetado em três dimensões que, por conta de um abalo sísmico, acaba se dobrando em quatro dimensões; e Um metrô chamado Möbius de Deustch (1979), no qual trens de um metrô desaparecem misteriosamente em função de uma topologia incomum das linhas, que exibem propriedades similares à fita de Möbius.

Do ponto de vista didático, acreditamos que as histórias baseadas em elementos anômalos se prestam muito bem à discussão crítica de conceitos pela maneira como nos colocam em uma situação distinta da convencional, permitindo a exploração de aspectos que uma análise mais linear não seria capaz de captar. Além disso, o fato de potencializar a atenção do leitor por meio do estranhamento estabelece uma relação com o conceito muito diferente da exposição linear, levando-o a atitude inquisitiva, ao levantamento de hipóteses, de possibilidades. Um trabalho didático relevante pode ser explorar a coerência, a relação da história com o conceito e a formulação de novas hipóteses que a própria narrativa acaba por induzir.

\section{Associativos:}

\section{[+científico][+extraordinário] [+conceitual] [+conexo] [-sobrenatural][-real][-explicado]}

Um processo de construção contrafactual é a associação semântica de ideias conhecidas, produzindo um efeito de conjetura sobre possibilidades. 0 sabre de luz de Guerra nas estrelas (Lucas, 1977) é um bom exemplo. Sabemos o que é sabre, sabemos o que é luz. Sabre de luz pressupõe a junção desses dois conceitos, criando um elemento novo, rico em possibilidades, que por sua construção associa um conceito científico a um contexto em que ele não é empregado. Quando esse é o principal procedimento usado na construção do elemento contrafactual, não havendo explicações [-explicado], temos um elemento que poderíamos chamar de 
associativo. Eles são em geral acessórios na composição da obra, de forma que a trama não gira em redor deles, o que, do ponto de vista didático, reduz um pouco as possibilidades.

No entanto, em alguns casos, eles desempenham um papel relativamente central. Assim é com o sabre de luz em relação à Guerra nas estrelas. Nesses casos, embora praticamente todo o conteúdo explicativo esteja apenas no nome e no aspecto visual, muita coisa pode ser deduzida a partir de sua relação com os demais elementos. Esse tipo de elemento, por possuir como ponto de partida a exploração de conceitos, pode dar base a atividades didáticas, que podem ser direcionadas ao exame do uso dos conceitos no contexto apresentado na obra. É isso que faz Cavellos (1999), que analisa o sabre de luz do ponto de vista físico, levantando questões que poderiam perfeitamente ser abordadas em sala de aula: os sabres de luz podem ser lasers? Por quê? Aí poderiam entrar discussões conceituais ligadas ao princípio da superposição, que implica na independência dos raios de luz e, portanto, proíbe um laser de "bater" no outro. Poderia se esperar que os alunos explicassem porque seria impossível construir esse tipo de espada utilizando lasers.

Outro caminho poderia ser colocar em xeque o próprio princípio da superposição e tentar extrair daí consequências, o que é muito difícil de fazer, mas muito importante também. Não seria tentar "salvar" o filme, como fazem os aficionados, mas usá-lo para examinar o conhecimento científico em seus limites, imaginando possibilidades alternativas de leis e suas consequências, o que levaria a outras questões sobre a formulação de hipóteses científicas.

\section{Apelativos:}

\section{[+científico][+extraordinário][+conexo] [-sobrenatural][-real][-possível] [-explicado][-conceitual]}

Em muitos casos, a história estabelece não mais que uma vaga conexão ou menção a uma possível justificativa científica dos predicados alternativos. Tal é o caso de Super-homem (Donner, 1978) e seus poderes. A justificativa científica nesse caso é muito simples: ele vem de outro planeta, o que é suficiente para conferir-lhe poderes especiais. Às vezes, também se utiliza um termo científico que possui significado preciso, mas as relações estabelecidas com o contexto do discurso faz com que esse significado se perca, tornando seu campo semântico menos definido. Esse é o caso dos cérebros positrônicos de lsaac Asimov (1978) em Eu, Robô. Embora o termo pósitron seja bem definido em física, no contexto da obra, ele é apresentado simplesmente para dar a ideia de um cérebro artificial de alta tecnologia. Apesar da terminologia científica, temos elementos desconectados de explicações ou de alusões conceituais definidas, portanto, marcados como [-explicado] e [-conceitual]. 0 vínculo que se estabelece com a ciência ocorre por relações vagas de contexto e não pela construção de uma ciência ficcional convincente. Há aqui, no entanto, um contrato implícito com o leitor de que esses artefatos e eventos têm uma explicação plausível, embora tal explicação seja tênue e permaneça na maior parte das vezes apenas no plano da expressão por meio das terminologias científicas.

Em certas obras, os autores constroem um sistema de elementos extrapolativos e emulativos, situando a história em um discurso forte de realidade, para então fazer surgir um elemento tipicamente apelativo - algo misterioso, sobre o qual os personagens e o leitor implícito têm a dúvida e o desconhecimento como núcleo principal da ação que se desenrola em torno dele. Nesse caso, o estranhamento é maximizado e geralmente não resolvido. Um exemplo típico disso é o monólito em 2001: Uma odisseia no espaço (Kubrick, 1968). Nesse caso, pouco se sabe sobre o comportamento ou o propósito do objeto. 0 efeito central desejado é justamente esse desconhecimento. Temos aqui elementos marcados como [+inusitado].

Um aspecto didático fundamental em todos os casos é que os elementos apelativos, 
sendo apresentados como [+extraordinário], tornam-se focos de atenção. Esse fato em si já justifica uma análise do ponto de vista dos conceitos e leis científicas. Não são tão ricos quanto os elementos especulativos, já que não estabelecem relações com uma ciência ficcional que poderia ser analisada à luz da "ciência real”, não possuem uma consistência em sua relação com outros elementos e não encontram quaisquer limites para suas possibilidades. Assim, talvez o melhor caminho em sala de aula seja analisar a possibilidade pura e simples daquele elemento existir, sem limites claros, sem relações mais rígidas, em função das leis e dos fenômenos conhecidos pelos alunos.

\section{Metonímicos:}

\section{[+científico][+extraordinário] [-sobrenatural][-real][-possível] [-explicado][-conceitual][-conexo]}

É comum, nas obras de FC, tentar-se atribuir um ar científico a elementos da história como uma das estratégias de construção da verossimilhança. A mera menção de uma palavra com aspecto científico ou a presença em cena de um objeto com aparência de instrumento sofisticado pode cumprir uma função que poderíamos denominar como metonímica, por não se referir ao objeto em si, mas a um campo ao qual ele supostamente pertence - no caso, o tecnocientífico. 0 processo é uma atribuição ad hoc de adjetivos inspirados no léxico da ciência como, por exemplo, no capacitor de fluxo da máquina do tempo automotiva em De volta para o futuro (Zemeckis, 1985). Nem o nome nem o aspecto visual do equipamento são capazes (nem pretendem, a nosso ver) de provocar o efeito associativo que os sabres de luz produzem. Isso por que nem a palavra capacitor nem a palavra fluxo estimulam, no leitor, associações com campos semânticos específicos que se apliquem à situação apresentada, e as referências ao elemento no discurso da obra não dão maiores esclarecimentos.

Ao contrário dos elementos anteriores, para os metonímicos, não vale a pergunta: isso poderia existir? Em contraste, imaginemos a pergunta: um ser de outro planeta poderia voar como faz o Super-homem? A pergunta faz sentido, embora, por se tratar de um elemento apelativo, necessitemos de hipóteses extratextuais (tal como: talvez ele use uma força antigravitacional). Por outro lado, é completamente inócuo perguntar se poderia existir um capacitor de fluxo, porque essa expressão não diz absolutamente nada mais do que "uma coisa técnica qualquer", não leva a conteúdos semânticos suficientemente definidos, é apenas um rótulo. Aqui se perde a conexão causal com os elementos do enredo, com um traço [-conexo].

Esses elementos podem parecer infrutíferos do ponto de vista didático, mas se adotarmos o ponto de vista do leitor leigo (por exemplo, o nosso aluno), veremos que em geral é indistinguível um elemento metonímico inventado de um real em termos científicos. Se um astrônomo em um filme fala em espectrofotômetro, como o espectador poderá distinguir isso de um multiplexador subespacial? Qual deles existe e qual não existe? Somente considerações extratextuais poderão decidir. No entanto, apenas isso já configura uma possibilidade didática relevante. Em uma atividade de sala de aula, a análise de um filme pode revelar um cuidado esmerado do autor em seguir de perto a terminologia e os usos cotidianos da ciência ou, ao contrário, uma série de termos com ar científico, mas que na verdade estão longe da precisão factual. Isso evidentemente não pode ser realizado sem um trabalho de pesquisa ou então o professor será um mero informante factual, dizendo: isso existe na ciência, aquilo não existe. Se espectrofotômetro é um aparelho que de fato existe, será que no filme ele é retratado tal como os espectrofotômetros reais? Se um multiplexador subespacial não existe, qual será a origem do termo empregado - como o autor inventou o termo e que relação ele poderia guardar com elementos provenientes da ciência e da tecnologia? Isso dá alguma pista a respeito do elemento ficcional tal como ele aparece retratado na obra? 


\section{Inalterados:}

\section{[+científico][-sobrenatural][-real] \\ [-extraordinário][-possível] [-explicado][-conceitual][-conexo]}

Feixes laser visíveis no vácuo do espaço, gravidade no interior das espaçonaves, são muito numerosos os "erros" cometidos pelos roteiristas. Em primeiro lugar, cabe definir melhor de que tipo de "erro" estamos falando e o porquê dessas aspas. Quando viajamos de carro por uma estrada, olhamos pela janela e vemos as árvores, as casas e tudo o mais na beira da estrada passar pela nossa janela em alta velocidade para trás. $\mathrm{Na}$ janela das naves espaciais da maioria dos filmes de FC, o mesmo ocorre com as estrelas, o que é completamente absurdo, dada a enorme distância que separa a nave das estrelas. Os roteiristas não percebem que isso é absurdo? Ao contrário. Eles estão, na verdade, trabalhando com convenções dadas pela experiência cotidiana. Estrelas passando para trás na janela dão ideia de movimento. Transporta-se assim, a experiência do automóvel para a espaçonave e passa-se a ideia de movimento, da velocidade e assim por diante, em flagrante violação com o que seria tal experiência no espaço. Como passar a ideia de movimento se não usarmos essa convenção? A opção de Kubrick (1968), em 2001: uma odisseia no espaço, foi por uma valsa de Strauss, mas será que isso cabe em um filme de aventura? Denominamos tais elementos de inalterados justamente por reiterarem a experiência cotidiana em um contexto onde, pelas leis naturais, ela não se aplicaria. São elementos que contrariam o conhecimento científico e a experiência real, mas que não são extraordinários, sendo antes ordinários fora do lugar.

No entanto, esse caráter peculiar acaba por chamar a atenção, e isso dá ensejo a algumas possibilidades didáticas. Uma delas, muito curiosa, foi proposta por Neves et al. (2000), que associa o movimento das naves em Guerra nas estrelas a concepções aristotélicas de movimento, enquanto as de 2001: uma odisseia no espaço estariam associadas a concepções newtonianas. 0 exame desse tipo de contraste ou uma análise crítica de tais elementos têm uma possibilidade importante. Uma discussão possível, junto com o exame crítico conceitual com os alunos (achar os "erros"), é o questionamento das motivações que os produtores tiveram em manter determinados elementos da obra como inalterados, apesar do flagrante desacordo com fatos amplamente conhecidos. A comparação dos fatos com as condições dadas pela experiência cotidiana e o levantamento de hipóteses sobre as consequências, no desenrolar da história, de considerarmos as leis científicas, podem ser desafios conceituais muito estimulantes.

\section{Considerações finais}

A FC tem sua própria maneira de falar sobre ciência, que é uma maneira que não encontramos mesmo em outras expressões ficcionais que falam da ciência. Ela é didática, porque se propõe a veicular ideias, mas não no sentido de explicar o que é a ciência ou ensinar conceitos científicos, embora isso possa ocorrer ocasionalmente. 0 que ela veicula, acima de tudo, são as questões que incomodam ou estimulam as pessoas, e que são questões originadas na ciência e na nossa relação sociocultural com ela.

Nesse sentido, a FC não é algo que incorporamos na sala de aula como mais um recurso didático, que se submete a nossos objetivos. Uma notícia de jornal, por exemplo, pode ser tirada de seu contexto e analisada em sala de aula, e certamente ainda estará veiculando posições ideológicas. lsso vale igualmente para a notícia e para a obra ficcional. No entanto, o compromisso que a notícia de jornal propõe ao leitor é completamente diverso do da obra de ficção. Esta lhe chama o envolvimento. A relação aqui é de sedução e ocorre no plano afetivo. A relação do leitor na notícia é com o conteúdo, mas com a obra de ficção é com a expressão. A forma de se dizer algo, na obra ficcional, suplanta o próprio conteúdo explícito em si. $\mathrm{Na}$ FC, a chamada função poética da linguagem se 
coloca a serviço de uma corrente utópica de desejos em relação ao mundo e ela faz isso por meio da indissociável relação entre expressão e conteúdo. Essa é uma dimensão que foge às nossas determinações didáticas e segue a "vontade" da própria obra ficcional.

Não fosse assim, seria desnecessário o próprio texto da obra em si. Bastaria, em vez de ler um conto de robô de lsaac Asimov, colocar a questão: um dia as máquinas poderão evoluir a ponto de termos dúvidas se elas serão ou não humanas? Acontece que essa questão, assim descrita, não abarca o efeito e a disposição de espírito que o conto proporciona. Da mesma forma, um artigo opinativo de um neurocientista ou de um cientista de computação poderia aprofundar a questão e até esboçar respostas e opiniões, mas ainda assim não estabeleceria o contrato de envolvimento afetivo que a obra ficcional propõe.

A FC trabalha em um limiar, que é a fronteira entre os sentimentos e a racionalidade. A racionalidade, a lógica das conclusões e o estabelecimento de relações causais podem ser explicitados em um discurso não literário. Os sentimentos que expressam angústias, preocupações, admiração, perplexidade - que são, por assim dizer, a matéria-prima da imaginação e da criatividade - só aparecem de forma contundente no trabalho ficcional.

Se fosse só por isso, entretanto, qualquer obra literária seria igualmente válida e teria as mesmas potencialidades do que uma de FC, desde que abordasse alguns dos temas em que estamos interessados. No entanto, o que a FC traz é justamente o estabelecimento de uma dialética entre o racional e o emocional que está no cerne de sua construção, e que está ligado àquilo que Suvin (1984) chamou de cognição.

Um trabalho com 2001: uma odisseia no espaço eventualmente poderia ficar restrito às questões físicas e astronômicas, à curiosidade sobre os aspectos racionalmente abarcáveis do ambiente lunar e do espaço, aos movimentos das espaçonaves, às características e a todos aqueles fenômenos que verificamos descritos na obra. Essa leitura, entretanto, estaria descartando aspectos fundamentais: a sensação de estar no espaço, o desejo (e o medo) que a humanidade venha a habitá-la, o medo dos perigos e o desafio de enfrentar as dificuldades impostas pela improvável insistência em viver em um ambiente espacial.

A FC, mais do que um possível recurso didático para o ensino de ciências, constitui um discurso social sobre a ciência. lsso implica que é possivel encontrar nas obras de FC visões, debates e questões a respeito das ciências em voga no momento de produção das obras. Assim, abordar ciência a partir da FC é mais do que simplesmente procurar conceitos veiculados em filmes ou livros. Para tal abordagem mais profunda da obra de ficção, são necessários instrumentos que permitam uma análise que vá além dos aspectos superficiais.

Nesse trabalho, apresentamos um caminho de análise, que parte do exame dos elementos ficcionais estáticos que aparecem nas histórias de FC. Embora tal análise não considere os aspectos dinâmicos do enredo, tais como os personagens, os conflitos e a trama, ainda assim é um ponto de partida revelador sobre as possibilidades de uso do trabalho ficcional no gênero. Verificamos que é possível, por meio de uma análise sustentada em elementos de teoria literária, identificar os mecanismos de constituição dos elementos contrafactuais em uma obra de FC. Tais mecanismos nos revelam mais do que procedimentos ficcionais. Eles evidenciam os possíveis caminhos epistemológicos que partem do conhecimento científico em direção ao discurso ficcional. Ao fazê-lo, abrem variadas possibilidades de abordagem didática. Cada modalidade de elemento traz em si um diferente potencial didático, que permite a exploração dos temas científicos sob um ou outro enfoque.

Como o próprio trabalho procurou evidenciar, esse instrumento de análise não esgota (nem pretende esgotar) as possibilidades da FC no ensino de ciências. Em nossas pesquisas, temos procurado levar em consideração outros aspectos da obra para compor um quadro ge- 
ral. Com isso, pretendemos também estabelecer metodologias mais gerais de análise para produtos culturais tecnocientíficos que possam (e têm sido) incorporados na educação científica formal.

A pergunta que nos fizemos no início do trabalho era se haveria uma relação íntima entre os "erros" conceituais dos estudantes e os "erros ficcionais" das obras. 0 que a análise mostra é que os tais "erros ficcionais" fazem parte de um espectro de mecanismos de se contar uma história que vão da suposta precisão conceitual dos elementos emulativos à sua flagrante violação nos inalterados. Tanto um quanto outro, assim como todos eles, são fruto de uma interlocução com o conhecimento científico. Se nos primeiros a ênfase está em simular esse conhecimento, é com a intenção de produzir um efeito maravilhoso ou assustador. Se nos últimos os conceitos básicos da ciência são ignorados, é porque isso é necessário para contar a história, porque trazem graça à narrativa. Tanto uns quanto outros são ficção e - nesse sentido - igualmente irreais. Certos ou errados, podem trazer tanto informações contraditórias à ciência, como auxiliar na compreensão conceitual.

A tal relação íntima, só a encontramos no ato de ler, como leitor crítico, aquilo que a obra escreve. E é na leitura crítica que a irrealidade da ficção se torna realidade sociocultural, já que toda obra literária fala da experiência humana de forma legítima, travestindo a realidade em fantasia. Nesse sentido, permite colocar o estudante frente à obra ficcional como um leitor crítico e levá-lo a questionar sua própria experiência vivida com os conceitos da ciência no contexto da vida humana. É justamente aí que encontramos o valor dos instrumentos de análise, que permitem ao professor que deseja usar a FC ver além da superfície. Uma abordagem intuitiva mostra aqui e ali as possibilidades que a FC dá na exploração de múltiplos aspectos de valor didático nas aulas de ciência. Procedimentos sistemáticos permitem um passo além: ajudam a tornar o professor um leitor crítico, capaz de ver nuances e mecanismos por trás do que parecia apenas uma aventura espacial divertida, levando-o a compreender estratégias narrativas e significados não percebidos. Somente quando o professor for capaz de ver algo além da superfície é que poderá mostrar aos alunos aquilo que não é imediatamente visível, de levá-los a refletir sobre a própria construção de seu conhecimento. 


\section{Obras analisadas}

ASIMOV, I. Eu, Robô. 10. ed. Rio de Janeiro: Exped-Expansão, 1978.

DEUSTCH, A. J. Um metrô chamado Möbius. In: ASIMOV, I. Para onde vamos? São Paulo: Hemus, 1979. p. 137-152.

DONNER, R. (Dir.). Super-homem - o filme. Vídeo. VHS. Cor. 143 min. Warner, 1978.

HEINLEIN, R. H. A casa quadridimensional. In: ASIMOV, I. Para onde vamos? São Paulo: Hemus, 1979. p. 93-11.

KUBRICK, S. 2001: uma odisseia no espaço. Vídeo. DVD. Cor. 148 min. Warner, 1968.

LEDER, M. (Dir.). Impacto profundo. Vídeo. DVD. Cor. 121 min. Paramount, 1998.

LUCAS, G. Guerra nas estrelas, episódio IV: a nova esperança. Vídeo. DVD. Cor. 121 min. Fox, 1977.

SCHAFFNER, F. J. (Dir.). 0 planeta dos macacos. Vídeo. DVD. Cor. 112 min. Fox, 2000.

ZEMECKIS, R. (Dir.). De volta para o futuro. DVD. Cor. 115 min. Universal, 1985.

\section{Referências bibliográficas}

ALLEN, L. D. No mundo da fiç̧ão científica. São Paulo: Summus, 1976.

ASIMOV, I. No mundo da ficção científica. Rio de Janeiro: Francisco Alves, 1984.

CAUSO, R. S. Ficção científica, fantasia e horror no Brasil: 1875 a 1950. Belo Horizonte: Editora UFMG, 2003.

CAVELLOS, J. A ciência de Star Wars. São Paulo: Market Books, 1999.

DARK, M. Using science fiction movies in introductory physics. Phys. Teach., v. 43. oct. 2005. p. 463-465.

DUBECK, L. W. et. al. Science fiction aids science teaching. Phys. Teach., may 1990. p. 316- 319. . Sci-Fi in the classroom: making a "deep impact" on young people's interest in science. Mercury, nov./dec. 1998. p. 24-28. Finding facts in science fiction films. Sci. Teach., apr./1993. p. 48.

DURANT, J. 0 que é alfabetização científica. In: MASSARANI, L. et al. (Org.). Terra incógnita: a interface entre ciência e público. n. 4. Rio de Janeiro: Vieira \& Lent; UFRJ; Casa da Ciência: FIOCRUZ, 2005. p. 13-26. Coleção Terra Incógnita.

ECO, U. Sobre o espelho e outros ensaios. Rio de Janeiro: Nova Fronteira, 1989.

FREUDENRICH, C. C. Sci-fi science: using science fiction to set context for learning science. The Science Teacher, v. 67, n. 8, nov. 2000. p. 42-45.

GILBERT, J. K.; ZYLBERSZTAJN, A. A conceptual framework for science education: the case study of force and movement. European Journal of Science Education, v.7, n. 3, 1985. p. 107-120.

GREIMAS, A. J. Semântica estrutural. 2. ed. São Paulo: Cultrix; Edusp, 1976.

KIRBY, D. A. Science consultants, fictional films and scientific practice. Social Studies of Science, v. 33, n. 2, apr. 2003. p. 231-268.

MARTIN-DIAZ, M. J. et al. Science fiction comes into the classroom: maelstrom II. Phys. Educ., v. 27, 1992. p. 18-23.

NEVES, M. C. D. et al. Science fiction in physics teaching: improvement of science education and history of science via informal strategies of teaching. Recen., v. 1, n. 2, 2000. p. 91-101.

ORWELL, G. A revolução dos bichos. Porto Alegre: Globo, 1971. 
PIETROFORTE, A. V. S.; LOPES, I. C. A semântica lexical. In: FIORIN, J. L. (Org.). Introdução à linguística. 4. ed. São Paulo: Contexto, 2005. v. Il, p. 111-135. Princípios de Análise.

RABKIN, E. The fantastic in literature. New Jersey: Princeton University, 1977.

SALTIEL, E.; VIENNOT, L. Que aprendemos de las semejanzas entre las ideas históricas y el razonamiento espontáneo de los estudiantes? Enseñanza de las ciencias, 1985. p. 137-144.

SNYDERS, G. A alegria na escola. São Paulo: Manole, 1988.

SOUTHWORTH, T. Modern physics and science fiction: a mini-unit for high school physics. The Physics Teacher, feb. 1987. p. 90-91.

SUVIN, D. Metamorfosis de la ciencia ficción: sobre la poética y la história de um género literario. Cidade do México: Fondo de Cultura Económica, 1984.

TODOROV, T. Introdução à literatura fantástica. 3. ed., n. 98, São Paulo: Perspectiva, 2004. Coleção Debates.

VIENNOT, L. Spontaneous reasoning in elementary dynamics. Eur. J. Sci. Educ., v. 1, n. 2, 1979. p. 205-222.

Recebido em 28.12.08

Aprovado em 18.08.09

Luís Paulo Piassi, doutor em Educação pela Universidade de São Paulo (2007), professor doutor da Escola de Artes, Ciências e Humanidades da USP, orientador do programa de pós-graduação interunidades em ensino de ciências da USP, atua em pesquisas sobre recursos didáticos para 0 ensino de ciências com ênfase na relação entre literatura, cinema e ensino de ciências.

Maurício Pietrocola, bolsista de Produtividade em Pesquisa 1C CNPq, orientador de doutorado, doutor em Epistemologie Et Histoire Des Sciences pela Universite de Paris VII - Universite Denis Diderot (França), livre docente pela Faculdade de Educação da Universidade de São Paulo, atua em ensino-aprendizagem com ênfase em métodos e técnicas de ensino e é membro correspondente internacional do Recherches Epistémologiques et Historiques sur les Sciences Exactes (França). 